Editorial

\title{
Undernutrition in Early Life and Chronic Diseases in Adulthood
}

\author{
Xianglong $\mathrm{Xu} \mathbf{u}^{1,2,3}$
}

${ }^{1}$ School of Public Health and Management, Chongqing Medical University, Chongqing, China

${ }^{2}$ Research Center for Medicine and Social Development, Chongqing Medical University, Chongqing, China

${ }^{3}$ The Innovation Center for Social Risk Governance in Health, Chongqing Medical University, Chongqing, China

Corresponding author: Xu, X. School of Public Health and Management, Chongqing Medical University, Chongqing, China. Tel: +8613594636537; Fax: +8602368485031; E-mail: xianglong1989@126.com

\section{Editorial}

The Chinese famine of 1959-1961 is the largest one in human history leading to approximately 30 million excess deaths ${ }^{[1-4]}$. During the Chinese famine, the lack of food, the serious shortage of nutrition, especially for pregnant women that need a lot of nutrition, also caused fetus or infant malnutrition and stunting.

Under nutrition refers to the pregnant mother's nutritional status, the fetus intrauterine nutrition and the first three years of the baby's nutritional status. The developmental origins hypothesis proposes that under nutrition in early life is associated with an increased risk of disease in adulthood ${ }^{[5]}$. Previous research suggested that increased risk of chronic diseases in adulthood might actually originate from adverse exposures or under nutrition during fetal period ${ }^{[6,7]}$. Studies also demonstrated that severe under nutrition during pregnancy adversely affects fetal brain development and delays the progress of the central nervous system and brain ${ }^{[8-11]}$. Prenatal under nutrition may induce a permanent physiologic response, which predisposes the fetus to disease development in later life ${ }^{[7,12]}$.

Emerging findings on the Chinese famine indicated that exposure to such famine in early life was related to elevated risk of diabetes ${ }^{[13]}$, metabolic syndrome, hypertension, short height ${ }^{[14,15]}$, and overweight ${ }^{[16]}$ among adults. In contrast to the Dutch and Leningrad famines, the Chinese famine was more recent, had longer duration (three years), was not due to war, and affected most areas of China. The effect of prenatal famine exposure on the risk of chronic diseases in adulthood may distinctly affect non-European populations; limited information on the effects of prenatal famine exposure in adulthood is published in developing countries ${ }^{[17]}$. Prenatal exposure to the Chinese famine provides scholars and researchers with an ideal population to explore the long-term consequences of severe fetal and early-life under nutrition of adult chronic disease in a non-European population.

In my opinion, it's necessary to focus on people's nutrition in early life, especially pay attention to pregnant women and infants' nutrition and health, and improve the nutritional status of pregnant women. This has important significance on the prevention of adult chronic diseases. With the improvement of people's living standard, it's important to pay more attention to the intake of nutrition. The government should make early intervention policies and take measures to reduce the occurrence of various chronic diseases.

\section{References}

1. Smil, V. China's great famine: 40 years later. (1999) BMJ 319(7225): 1619-1621.

2. Luo, Z., Mu, R., Zhang, X. Famine and overweight in China. (2006) Appl Econ Perspect Policy 28(3): 296-304.

\author{
Received Date: July 28, 2015 \\ Accepted Date: July 29, 2015 \\ Published Date: July 30, 2015
}

Citation: $\mathrm{Xu}, \mathrm{X}$. Undernutrition in Early Life and Chronic Diseases in Adulthood. (2015) J Food Nutr Sci 2(2): 79-80.

DOI: $10.15436 / 2377-0619.15 . \mathrm{e} 002$

3. Kung, J.K.S., Lin, J.Y. The cause of China's Great Leap famine, 1959-1961. (2003) Economic Development and Cultural Changes 52(1): 51-73.

4. St Clair, D., Xu, M., Wang, P., et al. Rates of adults schizophrenia following prenatal exposure to the Chinese famine of 1959-1961. (2005) JAMA 294(5): 557-562.

5. Godfrey, K.M., Barker, D.J. Fetal nutrition and adult disease. (2000) Am J Clin Nutr 71(5 Suppl): 1344S-1352S.

6. Koupil, I., Shestov, D.B., Sparén, P., et al. Blood pressure, hypertension and mortality from circulatory disease in men and women who survived the siege of Leningrad. (2007) Eur J Epidemiol 22(4): 223-234.

7. de Rooij, S.R., Painter, R.C., Holleman, F., et al. The metabolic syndrome in adults prenatally exposed to the Dutch famine. (2007) Am J Clin Nutr 86(4): 1219-1224.

8. Morgane, P.J., Austin-LaFrance, R., Bronzino, J., et al. Prenatal malnutrition and development of the brain. (1993) Neurosci Biobehav Reviews 17(1): 91-128.

9. Scholl, T.O., Hediger, M.L., Bendich, A., et al. Use of multivitamin/mineral prenatal supplements: influence on the outcome of pregnancy. (1997) Am J Epidemiol 146(2): 134-141.

10. Stabler, S.P. Vitamins, homocysteine and cognition. (2003) Am J Clin Nutr 78(3): 359-

Copy rights: $\mathrm{C} 2015 \mathrm{Xu}, \mathrm{X}$. This is an Open access article distributed under the terms of Creative Commons Attribution 4.0 International License. 
360.

11. Beard, J.L. Why iron deficiency is important in infant development. (2008) J Nutr 138(12): 2534-2536.

12. Lucas, A. Programming by early nutrition in man. (1991) Ciba Found Symp 156: 38-50.

13. Li, Y., He, Y., Qi, L., et al. Exposure to the Chinese famine in early life and the risk of hyperglycemia and type 2 diabetes in adulthood. (2010) Diabetes 59(10): 2400-2406.

14. Huang, C., Li, Z., Wang, M., et al. Early life exposure to the 1959-1961Chinese famine has long-term health consequences. (2010) J Nutr 140(10): 1874-1878.

15. Chen, Y., Zhou, L.A. The long-term health and economic consequences of the 1959-1961 famine in China. (2007) J Health Econ 26(4): 659-681.

16. Wang, Y., Wang, X., Kong, Y., et al. The great Chinese famine leads to shorter and overweight females in Chongqing Chinese population after 50 years. (2010) Obesity 18(3): 588-592.

17. Chen, H., Nembhard, W.N., Stockwell, H.G. Sex-specific effects of fetal exposure to the 1959-1961 Chinese famine on risk of adult hypertension. (2014) Matern Child Health J 18(3): 527-533. 